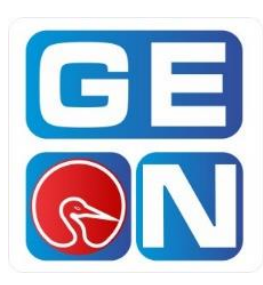

Revista GEON (Gestión, Organizaciones y Negocios.) ISSN: 2346-3910 en línea

revistageon@unillanos.edu.co

Universidad de los Llanos

Colombia

Sánchez Cortes, Rogelio Alberto; Vallejo Hernández, Laura;

Avila, Danae Duana ${ }^{i}$.

Normatividad de la Ley de patentes y marcas: una perspectiva mexicana

Revista GEON, Vol. 6, No. 2, 2019

Pág. 10-17

Disponible en: https://doi.org/10.22579/23463910.159

\footnotetext{
${ }^{\mathrm{i}}$ https://orcid.org/0000-0003-2286-2843
}

Esta publicación se encuentra bajo licencia: Creative Commons

ReconocimientoNoComercialSinObraDerivada 4.0 Internacional

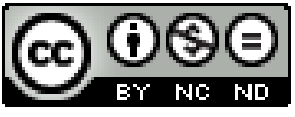

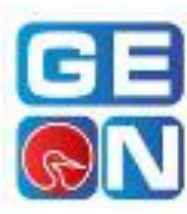

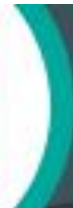

66

La realización que existe en las inversiones e innovaciones se promueve a través de la protección legal mediante patentes, marcas, modelos de utilidad, diseños industriales y secretos industriales
RevistaGEON in $9 f$ if 


\section{Normatividad de la Ley de patentes y marcas: una perspectiva mexicana}

\section{Regulations of the Law on Patents and Trademarks: A Mexican Perspective}

\section{Rogelio Alberto Sánchez Cortes ${ }^{1}$, Laura Vallejo Hernández², Danae Duana Ávila ${ }^{3}$}

Cómo citar este artículo / To reference this article:
Sánchez Cortes, R., Vallejo Hernández L., \& Duana Avila, D. (2019). Normatividad de la Ley de patentes y marcas: una perspectiva mexicana. Revista GEON (Gestión, Organizaciones $Y$

Negocios), 6(2), 10-17. Recuperado a partir de http://revistageon.unillanos.edu.co/index.php/geon/article/view/87

\begin{abstract}
Artículo de investigación:

Fecha de recepción: 2018/08/30

Fecha de aceptación: 2019/04/05

Esta publicación se encuentra bajo licencia: Creative Commons ReconocimientoNoComercialSinObraDerivada 4.0

La patente es una herramienta jurídica compleja que forma parte del derecho intelectual, oficialmente se le reconoce a alguien una invención y los derechos que de ella se derivan, definimos el concepto patente, describimos el sistema mexicano y se muestra la situación que guardan las marcas en México. La teoría muestra que los beneficios económicos derivados de la explotación de la patente y de las invenciones resultantes para su difusión y utilización públicas o privadas deben ser con beneficios a la sociedad lo que permitirá elevar el nivel técnico de un país
\end{abstract} Internacional.

\section{Resumen}

\section{Palabras claves: Publicidad, patentes, investigación, México}

\footnotetext{
${ }^{1}$ Dr. En Administración. Facultad de Ciencias Económico - Administrativas Universidad Autónoma de Tlaxcala, México, Rogelius_704@hotmail.com

${ }^{2}$ Mtra. administración. Facultad de Ciencias Administrativas. Universidad Autónoma de Tlaxcala, México, laura.vallejo@uatx.mx

${ }^{3}$ Dr. En economía, Universidad Autónoma del Estado de Hidalgo, PE administración, México duana@uaeh.edu.mx, https://orcid.org/0000-0003-2286-2843
} 


\section{Abstract}

The patent is a complex legal tool that is part of the intellectual right, it is officially recognized to someone an invention and the rights that derive from it, we define the patent concept, we describe the Mexican system and we show the situation that the brands keep in Mexico. The theory shows that the economic benefits derived from the exploitation of the patent and the resulting inventions for public and private dissemination and use must be with benefits to society, which will raise the technical level of a country.

Keywords: Advertising, patents, research, Mexico.

\section{Introducción}

La realización que existe en las inversiones e innovaciones se promueve a través de la protección legal mediante patentes, marcas, modelos de utilidad, diseños industriales y secretos industriales con la finalidad de fomentar la invención o mejora de productos de consumo o de utilidad social.

La creación de signos distintivos como marcas, avisos y nombres comerciales, y las denominaciones de origen, así como los derechos de autor quedan protegidos por el ordenamiento legal que protege la propiedad industrial en México, esto es, la Ley de la propiedad industrial (LPI) y su reglamento, y la institución encargada de su aplicación es el Instituto Mexicano de la Propiedad Industrial (IMPI).

De acuerdo con la Ley de la propiedad industrial, el IMPI tiene como atribución fomentar $\mathrm{y}$ proteger la propiedad industrial; es decir, los derechos exclusivos que otorga el Estado durante un tiempo determinado a las creaciones de aplicación industrial tales como un producto técnicamente nuevo, una mejora a una máquina o aparato, un diseño original para hacer más útil o atractivo un producto de fabricación novedoso, una marca o aviso comercial, una denominación que identifica un establecimiento, o una aclaración sobre el origen geográfico que distingue o hace especial un producto.

La Ley invenciones y marcas se expidió en 1975. Regulaba las patentes de invención y de las mejores; los certificados de invención; el registro de modelos; los dibujos industriales; los apoyos y facilidades respecto de los derechos solicitados por los trabajadores, la micro y la pequeña industria; el registro de marcas, las denominaciones de origen; los avisos; los nombres comerciales y la protección contra la competencia desleal determinando el posible plagio y el respeto al derecho de autor.

El problema. Existe una autoridad potestativa encargada de regular esta serie 
de normatividades que es el IMPI, así como las oficinas de propiedad industrial en otros países son los departamentos y oficinas del gobierno que cuentan con personal especializado, siendo examinadores y abogados que han sido entrenados en todas las ramas de la ciencia, y examinan concienzudamente cada solicitud para determinar si cumple con los lineamientos generales de los inventos y por consiguiente determinar técnicamente si se otorga la patente, una tarea que incluye investigaciones bastante profundas y exhaustivas.

Una patente es una concesión del gobierno por la cual se otorga al inventor el derecho de explotar económicamente de manera exclusiva su invención, así como adquiere derechos y por consiguientes acciones para prohibir a terceras personas: fabricar, utilizar, o vender su invento con las debidas sanciones respectivas sin olvidar que estamos inmersos en un sistema jurídico muy complejo y que su mecanismo de protección está muy limitado respecto a la protección en este ramo.

La LPI establece que el titular de una patente deberá explotarla por sí mismo o a través de una licencia, bien por la utilización o fabricación del invento en el país o mediante la importancia y venta subsecuente del producto patentado $\mathrm{u}$ obtenido por el proceso autorizado.

En México existen cuatro tipos que pueden, considerarse patentes:

1. Como molde, tipo o patrón y las patentes de invención, que se otorgan a los inventores de productos $\mathrm{o}$ procesos registrados por industrias $\mathrm{o}$ investigaciones;

2. Modelos de utilidad, que se otorgan a los utensilios, aparatos o herramientas, que presentan funciones novedosas o diferentes a las conocidas. Ésta es la invención o mejora de utensilios industriales de usos múltiples o destinados a la producción o salud;

3. Diseños industriales que son la combinación de colores, figuras o líneas que se incorporan a un producto industrial como pueden ser las marcas, diseños, o figuras que estimulan la adquisición o la identificación del producto a nivel comercial;

4. Modelos industriales que se constituyen como forma tridimensional que sirven da apariencia especial como puede ser el diseño de las figuras en autos, aviones comerciales o de uso bélico, etc.

Las patentes cuentan con una vigencia que comienza en la fecha de concesión y finaliza 20 años después de la fecha en que se solicitó la patente (fecha legal). Así mismo, para la conservación de los derechos que otorga una patente, el titular deberá cubrir los pagos anuales que establece la tarifa por concepto de aprovechamiento por los servicios que presta en Instituto.

Cuando se desea presentar una solicitud de patente se sugiere investigar las patentes que han sido otorgadas con anterioridad para asegurarse de que su idea no ha sido patentada. Esto se hace el Instituto Mexicano de la Propiedad Industrial (IMPI). 
El proceso de solicitud de una patente puede llegar a ser complejo y el IMPI no puede ayudar en la preparación de los papeles de solicitud, es por eso recomendable que los solicitantes contraten los servicios de un abogado especializado en la materia. Las solicitudes son asignadas a examinadores y abogados que son expertos en diferentes campos tecnológicos.

El invento para ser aprobado deberá ser nuevo, útil y no ser obvio para aquellos en la especialidad pertinente.

Una vez que la solicitud cumple con el examen de forma, (Art. 50 de la Ley) el cual sirve para verificar que los documentos e información necesarios estén debidamente integrados en el expediente de la solicitud de patente o registro.

Cuando es aprobado este examen y transcurridos 18 meses desde la fecha de presentación reclamada en la solicitud de patente, se produce a la publicación de ésta en la Gaceta de la Propiedad Industrial.

Después de la publicación se produce a la realización del examen de fondo, el cual permite constatar que la invención sea patentable, siendo nueva, resultando de una actividad inventiva y aplicable en la industria o en el comercio. Si la solicitud reúne los requisitos de patentabilidad establecidos en la LPI, se notifica al solicitante para que proceda a efectuar el pago de la tarifa por expedición de título que incluye la primera anualidad.

Efectuando el pago, se procede a la elaboración y entrega del título correspondiente el cual otorga el derecho a explotar la forma exclusiva la patente.
Deberán pagarse posteriormente las demás anualidades para la conservación de los derechos de propiedad industrial, en el tiempo y forma que señale la tarifa.

Si existen observaciones en el examen de fondo, el IMPI solicitará las aclaraciones correspondientes mismas que deberán ser atendidas en un plazo no mayor de 2 meses. En caso contrario se considerará abandonada la solicitud.

El tiempo promedio en que se otorga una patente en México es de 30 meses.

\section{Ley de la propiedad industrial}

En este apartado se presenta un extracto de la Ley para dar fundamento a los trámites y requisitos en materia de patentes, así como los derechos y obligaciones de los solicitantes.

A continuación, las principales modificaciones para trámite, otorgamiento y conservación de derechos de patentes y registros de modelos de utilidad.

Artículo 1. Disposiciones generales y conceptos. Las disposiciones de esta Ley son de orden público y de observancia general en toda la República, sin perjuicio de lo establecido en los tratados internacionales de los que México sea parte. Su aplicación administrativa correspondiente al Ejecutivo Federal por conducto del Instituto Mexicano de la Propiedad Industrial.

Artículo 2. Conceptos. Para efectos de este título se considerará como:

- Nuevo, a todo aquello que no se encuentre en el estado de la técnica. 
- Estados de la técnica, al conjunto de conocimientos técnicos que se han hecho públicos mediante una descripción oral o escrita, por la explotación o por cualquier otro medio de difusión o información en el país o en el extranjero.

- Actividad inventiva, al proceso creativo cuyos resultados no se deduzcan del estado de la técnica en forma evidente para un técnico en la materia.

- Aplicación industrial, a la posibilidad de que una intervención puede ser producida o utilizada en cualquier rama de la actividad económica

- Reivindicación, a la característica esencial de un producto o proceso cuya protección se reclama de manera especial y especifica en la solicitud de patente o registro y se otorga, en su caso, el titulo correspondiente $\mathrm{y}$,

- Fecha de presentación, a la fecha en que se presente la solicitud en el Instituto, o en las Delegaciones y Subdelegaciones Federales de la SECOFI en el interior del país, siempre y cuando se cumpla con los requisitos que señala la Ley y su reglamento.

\section{Artículo 16. Lo que no es patentable:}

- Serán patentables las invenciones que sean nuevas, resultado de una actividad inventiva y susceptibles de aplicación industrial, en los términos de la Ley,

Excepto:

- Los procesos esencialmente biológicos para la reproducción y propagación de plantas y animales.

- El material biológico y genético tal como se encuentra en la naturaleza
- Las razas y animales

- El cuerpo humano y las partes vivas que se componen y

- Las variedades de vegetales.

Artículo 19. Lo que no son invenciones:

- No se considerarán invenciones para los efectos de la Ley:

- Los principios teóricos y científicos

- Los descubrimientos que consistan en dar a conocer o revelar algo que ya existía en la naturaleza, aun cuando anteriormente fuese desconocido para el hombre;

- Los esquemas, planes, reglas y métodos para realizar actos mentales juegos o negocios y los métodos matemáticos;

- Los programas de computación;

- Las formas de presentación de información;

- Las creaciones estéticas y las obras artísticas o literarias

- Los métodos de tratamiento quirúrgico, terapéutico o de diagnóstico aplicables al cuerpo humano y los relativos a animales, $\mathrm{y}$

- La yuxtaposición de invenciones conocidas o mezclas de productos conocidos, su variación de forma, de dimensiones o de materiales, salvo que en realidad se trate de su combinación o función de tal manera que no puedan funcionar separadamente $o$ que las cualidades o funciones características de las mismas sean modificadas para obtener un resultado industrial no obvio para un técnico en la materia. 


\section{Los modelos de utilidad}

Concepto. Esta es otra modalidad que está encaminada principalmente a mejorar las patentes existentes respecto de alguna modificación o configuración estructural, puede ser que den una función diferente pero generan ventajas en su función, cabe destacar que este modelo de utilidad también es generado por la inventiva en mejora de las disposición por lo tanto ésta genera un propio derecho y un propio beneficio, cabe destacar que algunos elementos patentados más en el caso de los industriales y por el avance tecnológico han quedado obsoletos y en desuso, por lo tanto se tiende a establecer una mejora o actualización, éste es denominado Modelo de Utilidad, el cual se define desde el punto de vista legal y en función a la ley de Propiedad Industrial en su artículo 28 y dice:

$<<$ Se consideran modelos de utilidad los objetos, utensilios, aparatos o herramientas que, como resultado de una modificación en su disposición, configuración, estructura o forma, presenten una función diferente respecto de las partes que lo integran o ventajas en cuanto a su utilidad $>>$.

\section{Vigencia de los modelos de utilidad}

Tienen una vigencia de 10 años improrrogables y para su tramitación se aplicarán, en lo conducente, las reglas de las patentes, a excepción de los artículos 45 y 52.

El artículo 80 de la Ley, establece que las patentes y los registros caducan; es decir, los derechos que amparan caen en el dominio público por no cubrir el pago (anualidades) a que están sujetos en el tiempo que fije la referida tarifa.

\section{Diseños industriales}

Concepto. Cualquier dibujo o forma para decorar un producto o para darle una apariencia o imagen propia. (si el diseño es bidimensional se denomina dibujo, y si es tridimensional se le llama modelo). Un dibujo industrial es toda combinación de figuras, líneas o colores que se incorporan a un producto industrial. El modelo es toda forma tridimensional que sirve de patrón para la fabricación de un producto.

El titulo o certificado que se expide es el: Registro de Dibujo Industrial, Registro de Modelo Industrial.

\section{Condiciones de registro}

- El diseño (sea dibujo p modelo) debes ser nuevo, es decir, de creación independiente y que difiera en grado significativo de diseños conocidos o de combinaciones de características conocidas de diseños (novedad mundial)

- El diseño (sea dibujo o modelo) debe poder ser utilizado o producido en la industria (explotación industrial).

\section{Vigencia del diseño industrial}

La vigencia del derecho exclusivo de explotación a partir de la solicitud es de 15 años. Una vez terminada la vigencia, si así lo dispone el titular o apoderado del diseño, éste se podrá nuevamente renovar. 
El registro de los diseños industriales, así como cualquier otro registro hecho por el IMPI tienen fecha de caducidad, razón por la cual se les debe dar su debido mantenimiento a los registros, es decir, estar al corriente en las cuotas y verificar periódicamente la fecha en que dicho registro vence, para así poder renovarlos nuevamente. Cualquier registro que cumpla con la caducidad, pasará a formar parte del dominio público.

\section{Protección jurídica}

El díselo sólo está protegido contra el uso no autorizado por su titular en México. La protección jurídica de los derechos de propiedad industrial únicamente se otorga en el país donde esta solicitada y concedida.

Si se desea la misma protección jurídica de los derechos de propiedad industrial en el extranjero, se deberá presentar la solicitud en cada país, reclamando el derecho de prioridad (artículos 40 y 41 de la Ley)

\section{Tramite}

Una vez presentada la solicitud se procede a la realización de examen de forma para verificar que los documentos e información sean los necesarios, según la LPI, los cuales deberán estar debidamente integrados en el expediente de la solicitud de registro.

Una vez realizado el examen de fondo, si la solicitud reúne los requisitos establecidos en la LPI, se notifica al solicitante para que proceda a efectuar el pago de la tarifa por expedición de título y, en su caso, pagará una o cinco anualidades.

Efectuando el pago, se concede a la elaboración y entrega del título correspondiente. Deberán pagarse posteriormente las demás anualidades para la conservación de los derechos de propiedad industrial, en el tiempo y forma que señale la tarifa.

La tarifa por concepto de aprovechamiento por los servicios que presta el Instituto establece que los inventores independientes, la micro y pequeña industria, las instituciones de educación pública y los institutos de investigación y desarrollo tecnológico del sector público pagaran únicamente el 50\% de las cuotas de los derechos que correspondan. Esto con el fin de ayudar al desarrollo industrial del país.

El reclamo de la <<prioridad>> para los diseños industriales deberá hacerse dentro de los seis meses siguientes a la fecha inicial de la solicitud. La prioridad es la fecha en que se solicitó el registro.

\section{Bibliografía}

G. Steiner (1983). Planeación estratégica (1ra.Edicion), México, CECSA.

Organización internacional de Trabajo (2012), concepto de microempresas (en línea) consultado

(2012). http://deconceptos.com

Gustavo (2008), herramientas para planificación de proyectos (en línea) consultado 2012. http://www.empresores.com/foros/8255herramienta-planificacion-de-proyectos. 
Ley de la Propiedad Industrial (LPI), DOF: 27-VI-1991

OMPI: Organización Mundial de la Propiedad Intelectual. PTC Glosario Visto: 12-X-2016, en: http://www.wipo.int/pct/es/texts/glossary. html

Organización Mundial de la Propiedad Intelectual. ¿Qué es Propiedad Intelectual? Visto: 12-X-2016, en: http://www.wipo.int/edocs/pubdocs/es/ intproperty/450/wipo_pub_450.pdf

Organización Mundial de la Propiedad Intelectual. Declaración Mundial sobre la propiedad Intelectual. (Publicación de la OMPI N ${ }^{\circ}$ 836(S) Nueva York, Estados Unidos de América: Editor. ISBN 92-805-
0952-7. Visto: 12-X-2016, en: http://www.wipo.int/edocs/pubdocs/es/ge neral/836/wipo_pub_836.pdf

Reglamento de la Ley de la Propiedad Industrial. (1994). Última reforma 10-VI2011, en: http://www.diputados.gob.mx/LeyesBibli o/regley/Reg__LPI.pdf

Saul Trejo Fuentes (2008), Teoría de la organización (en línea) consultado 2012. http://www.gestiopolis.com/administracio n-estrategica.

Ivan Dimitrie Moyasevich B. (2005), temas de ingeniería industrial (en línea)consultado 2012. http://perso.wanadoo.es

Mgs. Victor Chininin (2010), planeación estratégica (en línea) consultado 2012. 